\title{
GbAt11 gene cloned from Gossypium barbadense mediates resistance to Verticillium wilt in Gossypium hirsutum
}

\author{
QIU Tingting ${ }^{\dagger}$, WANG Yanjun ${ }^{\dagger}$, JIANG Juan, ZHAO Jia, WANG Yanqing and QI Junsheng ${ }^{*}$
}

\begin{abstract}
Background: Gossypium hirsutum is highly susceptible to Verticillium wilt, and once infected Verticillium wilt, its yield is greatly reduced. But G. barbadense is highly resistant to Verticillium wilt. It is possible that transferring some disease-resistant genes from $G$. barbadense to $G$. hirsutum may contribute to $G$. hirsutum resistance to Verticillium wilt.

Result: Here, we described a new gene in G. barbadense encoding AXMN Toxin Induced Protein-11, GbAt11, which is specifically induced by Verticillium dahliae in $G$. barbadense and enhances Verticillium wilt resistance in $G$. hirsutum. Overexpression in G. hirsutum not only significantly improves resistance to Verticillium wilt, but also increases the boll number per plant. Transcriptome analysis and real-time polymerase chain reaction showed that GbAt11 overexpression can simultaneously activate FLS2, BAK1 and other genes, which are involved in ETI and PTI pathways in G. hirsutum.

Conclusion: These data suggest that GbAt11 plays a very important role in resistance to Verticillium wilt in cotton. And it is significant for improving resistance to Verticillium wilt and breeding high-yield cotton cultivars.
\end{abstract}

Keywords: Gossypium barbadense, GbAt11, Verticillium wilt, resistance

\section{Introduction}

Verticillium wilt is a highly destructive soil-borne fungal disease of plants that affects an extensive range of host species, including many agricultural crops (Burpee and Bloom 1978; Fradin et al. 2011; Qi et al. 2016). Verticillium wilt of cotton is caused by Verticillium dahliae, but how the pathogen causes the disease of plants remains to be clarified (Gao et al. 2011). However, there is an accumulative evidence to show that the toxin produced by $V$. dahliae is the main pathogenic factor, for example, a protein or glycoprotein is mainly responsible for the wilt symptoms. Studies on the resistance mechanisms of plants to Verticillium wilt found two genetic loci, Ve1

\footnotetext{
* Correspondence: junshai@cau.edu.cn

${ }^{\dagger}$ Qiu $T T$ and Wang YJ contributed equally to this work.

State Key Laboratory of Plant Physiology and Biochemistry, Department of Plant Science, College of Biology Science, China Agricultural University,
} Beijing 100193, China

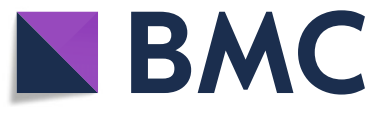

(อ The Author(s). 2020 Open Access This article is licensed under a Creative Commons Attribution 4.0 International License, which permits use, sharing, adaptation, distribution and reproduction in any medium or format, as long as you give

appropriate credit to the original author(s) and the source, provide a link to the Creative Commons licence, and indicate if changes were made. The images or other third party material in this article are included in the article's Creative Commons licence, unless indicated otherwise in a credit line to the material. If material is not included in the article's Creative Commons licence and your intended use is not permitted by statutory regulation or exceeds the permitted use, you will need to obtain permission directly from the copyright holder. To view a copy of this licence, visit http://creativecommons.org/licenses/by/4.0/. in potato can enhance resistance to $V$ dahliae (Kawchuk et al. 2001; Simko et al. 2004). Although it has been shown that $V e 1$ gene is functional only in tomato (Fradin et al. 2011; Fradin et al. 2009), GbVe1, which is a homolog of the tomato Vel cloned from Gossypium barbadense, is highly resistant to Verticillium wilt, and its overexpression in Arabidopsis thaliana has confirmed the disease resistance function of this gene (Zhang et al. 2011; Zhang et al. 2013). Based on the genetic principle of immune response induction, we treated G. barbadense with purified $V$. dahliae filtrate protein, extracted RNA, and cloned 11 full-length cDNAs of specific genes (GbAt1 - GbAt11) using suppression subtractive hybridization (SSH). The objective of this study was to analyze the molecular role of GbAt11 gene in resistance of cotton to Verticillium wilt. 
Recently, considerable progress has been made in understanding the immune mechanisms underlying the response of plants to pathogen infection. Studies have shown that plants identify pathogenic microorganisms by the presence of specific molecular motifs, known as pathogen-associated molecular patterns (PAMP)(Ozinsky et al. 2000), for example, the flagellin protein Flag22 on the surface of Pseudomonas syringae, the bacterial elongation factor EF-Tu, and chitin (Asai et al. 2002; Wan et al. 2008). When plants contact Flag22, the receptor protein FLS2 is activated on the surface of plant cells and is up-regulated through MAPK kinase signal transduction and transcription factor WRKY29 expression (Asai et al. 2002; Gomez-Gomez and Boller 2000; Adachi et al. 2015), therefore causing the production of reactive oxygen species (ROS) and the accumulation of callose at the infected site, thus protecting against the pathogen invasion (Nurnberger et al. 2004). FLS2mediated disease resistance pathways are also involved in the BAK1 element in the brassinosteroids (BR) pathway, which is the co-receptor of both BR and FLS2 (Albrecht et al. 2008; Lin et al. 2013). After FLS2 is activated by Flag22, BAK1 is recruited to form a complex, and then transfers the resistance signal to downstream by a process called PAMP-Triggered-Immunity (PTI)(Albrecht et al. 2012). Some bacterial pathogens have evolved effectors to inhibit PTI; however, plants have evolved proteins to counteract these effectors, which can relieve the inhibition of effectors on PTI through a process called effector-triggered-immunity (ETI). Thus, host plants and their pathogens co-evolve during this mutually antagonistic process.

Since GbAt11 was induced in G. barbadense with high resistance to Verticillium wilt, we studied the function of GbAt11 in resistance to Verticillium wilt, and the GbAt11-G. hirsutum lines significantly increased resistance to Verticillium wilt. Similarly, we found that overexpression of GbAt11 can up-regulate the expression of FLS2, BAK1 and other related disease resistance genes. Therefore, we speculate that GbAt11 plays an important role in the process of resistance to Verticillium wilt and is beneficial for improving resistance to Verticillium wilt and breeding high-yield cotton cultivars. And it also has reference value for the study of the mechanism of plant antifungal diseases.

\section{Materials and methods Materials}

G. barbadense variety $\mathrm{H} 7124$ seeds were purchased from the National Cotton Seeds Repository (China). Seeds of G. hirsutum variety JM169 were provided by the Institute of Cotton, Hebei Academy of Agriculture and Forestry Sciences (Shijiazhuang, Hebei). G. barbadense and G. hirsutum were grown in greenhouse at $25^{\circ} \mathrm{C}$ with a
12 h/12 h (day/night) cycle, and G. hirsutum JM169 was used as the wild type (WT) control. All transgenic plants used in this study are in JM169 background.

\section{Methods \\ GbAt11 gene cloning and sequencing}

The G. barbadense seedlings were divided into two groups, and one was soaked in a solution of $V$. dahliae toxin, while the other was soaked in water as the control. Three plants were sampled at $6,12,18$, and $24 \mathrm{~h}$ of treatment, respectively, while their total RNA was extracted, and mRNA was purified, then used as SSH (Diatchenko et al. 1996). A total of 11 specific gene fragments were obtained, cloned into T-vector and sequenced by Sangon Biotech Co. Ltd. From the sequencing results, they were named GbAt1 to GbAt11. This study focused on exploring the role of GbAt11 gene. Basic local alignment search tool (Blast) searches were performed against GenBank to find the full-length cDNA sequence. The chromosomal location of the GbAt11 gene was obtained from an analysis at the website.

Specific real-time PCR detection of GbAt11 expression in G. barbadense and $G$. hirsutum

Seedlings of G. barbadense and G. hirsutum were grown in a greenhouse. Leaves were collected at the adult-plant stage from the same parts of the plants, soaked in $V d 991$ spore suspension $\left(1 \times 10^{6}\right.$ per $\left.\mathrm{mL}\right)$, sampled after $0 \mathrm{~h}, 4$ $\mathrm{h}, 8 \mathrm{~h}, 12 \mathrm{~h}$, and $24 \mathrm{~h}$, respectively, and total RNA was extracted from $100 \mathrm{mg}$ of powder. Then we used realtime polymerase chain reaction (RT-PCR) (Salin et al. 2005) to quantify the level of GhAt11-specific mRNA at different times. RNA was extracted with the EASYspin plant RNA rapid extraction kit (Beijing Aidlab biotechnologiesCo. Ltd), quantified, and the relative expression of GbAt11 mRNA was measured using RT-PCR after cDNA synthesis by reverse transcription. PCR primer sequences were designed as follows: forward primer $5^{\prime}$ AGGGTTTCGTCGTCTACT-3', and reverse primer 5' GATGCTTCTCCTCATAGG-3'. Amplification reactions $(20 \mu \mathrm{L})$ contained $10 \mu \mathrm{L}$ SYBR Premix Ex Taq, $0.6 \mu \mathrm{L}$ of each primer $(\mathrm{F}+\mathrm{R}), \quad 0.4 \mu \mathrm{L}$ ROX, $1-2 \mu \mathrm{L}$ cDNA, and $\mathrm{ddH}_{2} \mathrm{O}$ to $20 \mu \mathrm{L}$.

\section{Construction of the GbAt11 overexpression binary vector (the concentration of primary proteinsis quantified with spectrophotometer)}

We replaced the $\mathrm{Hyg}^{\mathrm{R}}$ gene with the $t f d A$ gene in the pCAMBIA1300 binary vector to make a vector called pSPT. We designed primers containing Sal1/KpnI restriction enzyme sites on both ends of the GbAt11 open reading frame (ORF); AT11-2-SalI-F: 5'-CGGTCG ACATG TCGATCGCGTTGGAACG-3', and AT11-2KpnI-R: 5'-CGGGTACCGTTATATTCAC GTACAT 
CAGCC-3', and obtained the target gene by reverse transcription of $G$. barbadense AXMN mRNA. The pSPT vector was digested with SalI and KpnI, then ligated with the target gene fragment using T4 DNA ligase to construct the recombinant binary vector containing the GbAt11 gene.

\section{Verticillium dahliae inoculations}

$V$. dahliae inoculations was conducted according to Fradin etc. (2009). The 2 3-week-old cotton plants were uprooted, and then the roots and (or) adult-stage cotton leaves were rinsed in water. Subsequently, the roots or petioles were dipped for $24-72 \mathrm{~h}$ in a suspension of $10^{6}$ conidia per $\mathrm{mL}$ of Czapek's medium dextrose broth (Difco) and harvested from 2-week-old Verticillium cultures on Czapek's medium dextrose agar (Oxoid). Control plants were treated similarly, but their roots were dipped in Czapek's medium without conidiospores. After dipping, the disease phenotype was recorded and photographed from $1 \mathrm{~h}$ to $72 \mathrm{~h}$.

\section{Screening of transgenic positive cotton lines}

Transformation of G. hirsutum was performed using the pistil drip method (Zhang and Chen 2012). Transgenic seeds were sown in the field, sprayed with 2,4-D at 30 $\mathrm{mg} \cdot \mathrm{kg}^{-1}$ after sprouting, and the plants with a completely unfolded true leaf were screened. DNA was extracted and plants were screened for the $t f d A$ gene and the target gene. Primers for $t f d A$ amplification were tfdA-F:5'-ATGAGA TCCATGGGTGAGCG-3', and tfdA-R:5'-AGAACG CAGCGGTTGTCC-3'. PCR was used to identify single copy transgenic plants based on the segregation ratio of the $T_{2}$ generation against 2,4-D. We first identified disease resistance in the single copy lines in the disease nursery (cotton stalks inoculated with Vd991 were crushed and evenly spreaded in the field every year, to ensure the uniformity of $V$. dahliae in the disease nursery), and then we selected lines L-213, L-214, and L-235 with good field resistance, treated with a $V$. dahliae spore suspension (concentration of $1 \times$ $10^{6}$ per $\mathrm{mL}$ ) for resistance identification in a disease assay. We next extracted total proteins from L-214 leaves, concentrated the GbAT11-Flag protein fusion using the Flag tag, fractionated the proteins on a denaturing polyacrylamide gel, and then detected the anti-Flag antibody by western hybridization.

\section{Transcriptome analysis}

Transcriptome analysis was performed by Beijing Biomarker Technologies Co. Ltd.

Subcellular localization of the GbAT11-GFP fusion protein We constructed the pCAMBIA:GbAT11-GFP recombinant expression vector and used it to transform
Arabidopsis thaliana. $\mathrm{T}_{2}$ generation transgenic seeds were sown on murashige and skoog basal medium (MS) medium, and after the GbAT11-GFP-expressing seedlings grew for 1 week, GFP fluoresence was observed with a laser scanning confocal microscope. The excitation and emitting wavelengths for GFP were 488 and $525 \mathrm{~nm}$, respectively. This allowed us to see whether GbAT11 was localized to the cell wall after treated with $V$. dahliae toxin. We treated the roots of transgenic Arabidopsis with 20\% sucrose solution to plasmolyze the cells in order to observe the membrane localization of GbAT11.

\section{Field disease resistance identification and examination of yield traits}

The test on Verticillium wilt resistance of plants carrying the endogenous At11 gene, transgenic plants overexpressing GbAt11, and G. hirsutum carrying a TALENT knockout of GhAt11 was carried out in a field disease nursery inoculated with the $V d 991$ in Shandong province. There were two lines of each variety, a total of 60 plants. Plants were examined for symptoms of Verticillium wilt on June 20 and August 20, and were classified into five levels based on the degree of morbidity (ratings of 0 to 4 ). We calculated the Verticillium wilt disease index according to the formula (1), for every line, and counted the average number of bolls per plant on September 10. And the same test was carried out at the test base of China Agricultural University (Hebei province, in north-central China).

\section{Results}

Screening of Gossypium barbadense-response genes induced by Verticillium wilt using suppressive subtraction hybridization

Gossypium barbadense possesses the highest level of resistance to verticillium wilt among the four cotton species, while the widely cultivated G. hirsutum is highly susceptible. We soaked seedlings of G. barbadense and G. hirsutum in a solution of purified proteins secreted by $V$. dahliae, and necrotic lesions were found present on the leaves of G. barbadense after $72 \mathrm{~h}$, while the entire leaves of $G$. hirsutum were withered (data not shown). We induced the verticillium wilt-resistant $G$. barbadense with a solution of purified $V$. dahliae proteins, and obtained 11 specific genes (GbAt1-GbAt11) using SSH.

We initially focused on GbAt11 because its expression appeared to be strongest in G. barbadense induced by $V$. dahliae. The full-length GbAt11 cDNA is $768 \mathrm{bp}$, and the predicted molecular mass of the protein is about $27 \mathrm{kd}$. The N-terminal ORF from G. barbadense has an additional 17 amino acids than the predicted protein from G. hirsutum. In addition, BLAST searches confirmed that no GbAt11-like gene was present in A. thaliana. 
Further DNA sequence comparison and amino acid sequence analysis predicted that GbAT11 has $49.08 \%$ and $48.76 \%$ amino acid sequence homology with MTD1 (Methylene-tetrahydrofolate dehydrogenase $[\mathrm{NAD}(+)]$ ) and Jatropha curcas serine/arginine repetitive matrix protein 2-like (SRRM2-like), respectively. But the strange thing is that the primary amino acid sequence of GbAT11 is closely similar to Damaged DNA-binding 2, putative isoform 1 (DDB2), but the gene has not yet been reported, and the most similar homolog gene is related with the uncharacterized protein LOC105800652 in NCBI (National Center for Biotechnology Information). A further search of the COTTONGEN (http://www.cottondb.org) indicated that the GbAt11 gene is located on Chromosome 9 in G. raimondii, so GbAt11 is a new gene which may be located on chromosome 9 in $G$. hirsutum.

\section{GbAt11 gene expression is specifically induced by Verticillium dahliae in Gossypium barbadense}

In order to investigate the relationship between GbAt11 and $V$. dahliae, and to explore transcriptional difference between G. barbadense and G. hirsutum, we collected young leaves at the adult-plant stage from the same parts of wild G. barbadense and wild G. hirsutum. Leaves were dipped in filtration of $V d 991$ (spore concentration of $1 \times 10^{6}$ per $\mathrm{mL}$ ). Total RNA was extracted from samples at different induction times, then reversely transcribed into cDNA to determine the relative level of GbAt11 transcription by RT-PCR. Results showed that: (1) transcription of GbAt11 increased 10fold in seedlings treated with $V d 991$ for $4 \mathrm{~h}$ in G. barbadense, and then declined to the initial level. Transcription of GbAt11 increased significantly when induced for $8 \mathrm{~h}$, and peaked at $24 \mathrm{~h}$ at more than 70 fold. These results indicated that the GbAt11 gene is specifically induced by $V$. dahliae in G. barbadense. (2) Transcription of GhAt11 increased slightly in G. hirsutum, but the leaves were heavily wilted at $12 \mathrm{~h}$, and RNA were failed to be extrated. These results showed that expression of GbAt11 is specifically induced by $V$. dahliae, and is closely related to the host resistance response to pathogenic bacteria. In response to inducing by $V$. dahliae, GbAt11 is specifically overexpressed in Verticillium wilt-resistant G. barbadense, but the homolog of this gene was not specifically induced in $G$. hirsutum which is susceptible to Verticillium wilt, and its leaves appeared serious wilting within $12 \mathrm{~h}$ (Fig. 1).

\section{GbAt11 overexpression enhances resistance to Verticillium wilt in Gossypium hirsutum}

Because GbAt11 is specifically induced in highly Verticillium wilt-resistant G. barbadense, we speculated that overexpression of GbAt11 could improve the resistance to Verticillium wilt in susceptible G. hirsutum. To test this hypothesis, we transformed the wilt-susceptible $G$.

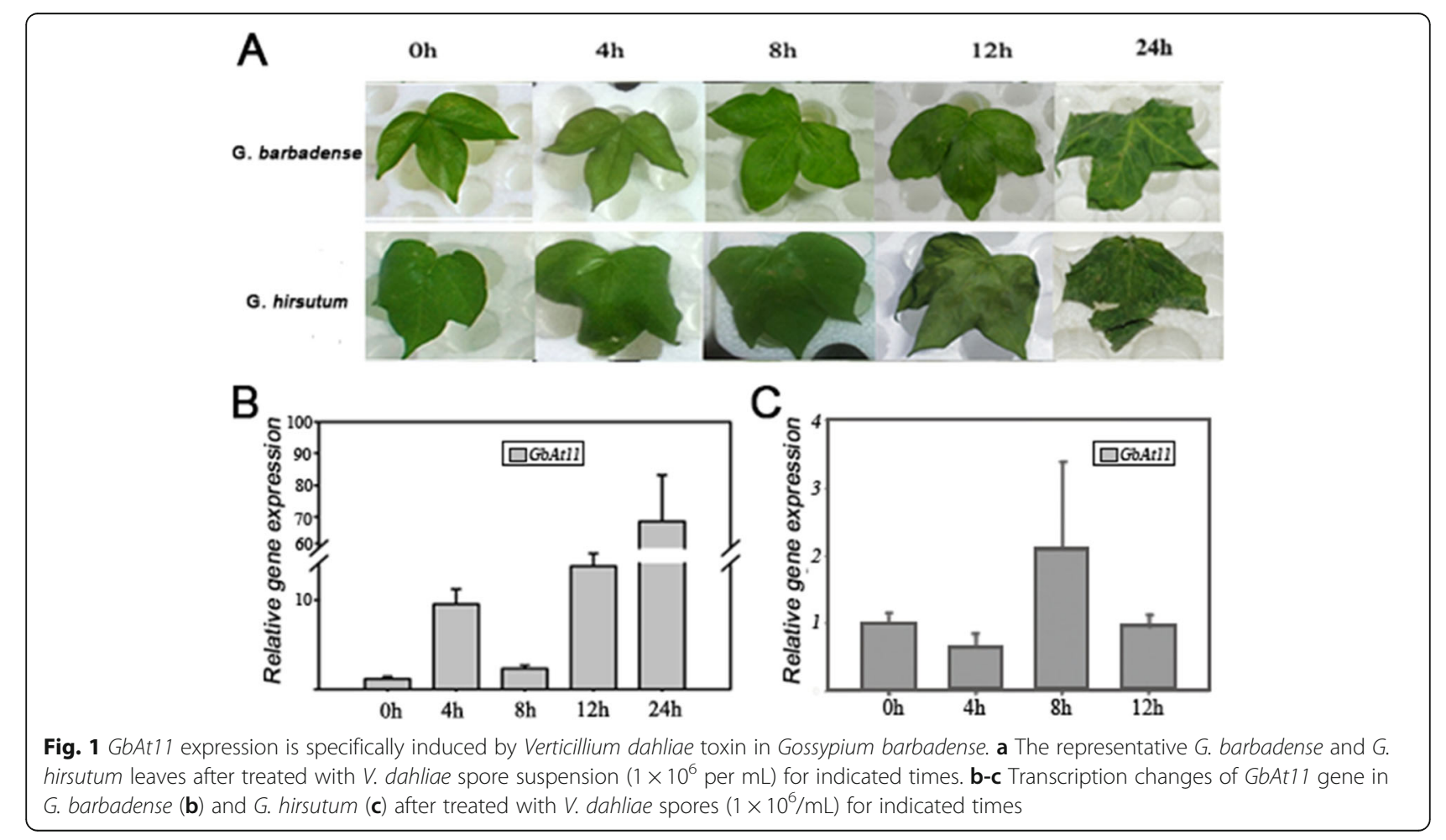


hirsutum variety JM169 (WT) with GbAt11 and obtained 52 transgenic plants. Verticillium wilt-resistance ratings of field and greenhouse in a disease nursery were performed on the $T_{2}$ generation plants of 17 transgenic lines. L-214 is a high-yielding line with good disease resistance. As shown in Fig. 2a, compared with the parental line (WT), L-214 showed the highest disease resistance, followed by L-213, but L-235 showed poor disease resistance.

In order to further confirm the role of GbAt11 gene in disease resistance, we extracted total proteins from leaves of transgenic L-214 (the flag tag fused to the Cterminal end of GbAT11) and the parental line WT (No flag tag). Anti-flag antibody-coated magnetic beads were incubated with the total protein to capture the flag tagged GbAT11 (IP). Then we used anti-flag antibody for Western blot detection, which showed that transgenic L-214 had one hybridizing band between 25 and $35 \mathrm{kd}$, which was absent in JM169, confirming the presence of GbAT11 protein in L-214 (Fig. 2b). To shed light on the relationship between the level of GbAt11 transcription and disease resistance, we quantified GbAt11 expression in transgenic lines L-213, L-214, and L-235 using real-time PCR. The results showed that GbAt11 expression was the highest in L-214 with the best
Verticillium wilt resistance, and successively decreased in lines L-213 and L-235 (Fig. 2c), corresponding to the relative levels of Verticillium wilt resistance in the two lines (Fig. 2c and d). In subsequent experiments, L-214 was selected as its excellent disease resistance.

The disease index was calculated as formula (1):

$$
\text { Index }=\frac{\sum \text { disease rating } c \times \text { plant number } c}{4 \times \text { total plant number }} \times 100
$$

Here, disease rating $c$ was scored in five grades $(0$ to 4$)$ based on the severity of Verticillium wilt symptoms in cotton. Grade 0, health, no disease symptom of leaves; grade 1, leaves have slight disease symptoms; grade 2, leaves have disease symptoms in moderate degree; grade 3 , leaves have remarkable disease symptoms; And grade 4, leaves have severe disease symptoms. Plant number $c$ was the number of plants corresponding to the rating of disease severity. The '4' was grade 4 which was the highest grade.

\section{GbAt11 overexpression in Gossypium hirsutum up- regulates transcription of several key genes in the immunity pathways}

Given that GbAt11 overexpression can improve disease resistance in plants, further transcriptome analyses
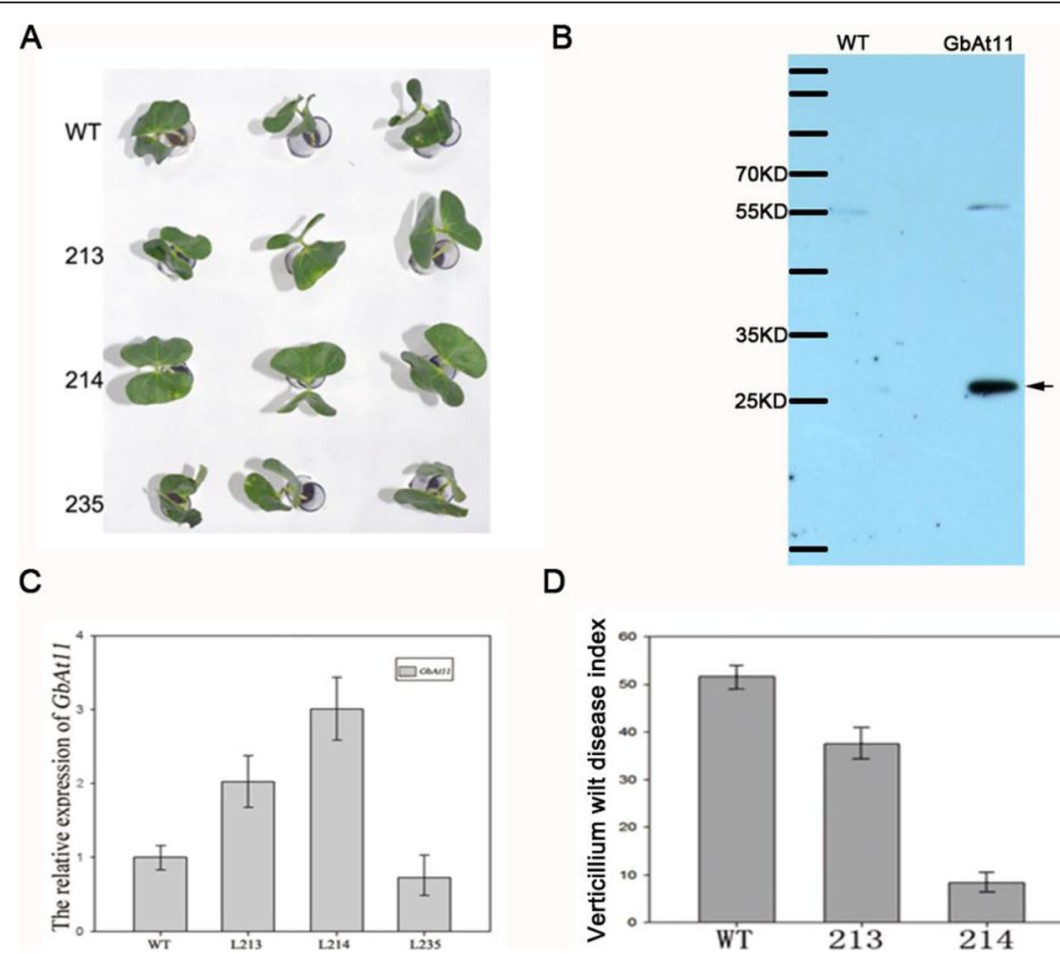

D

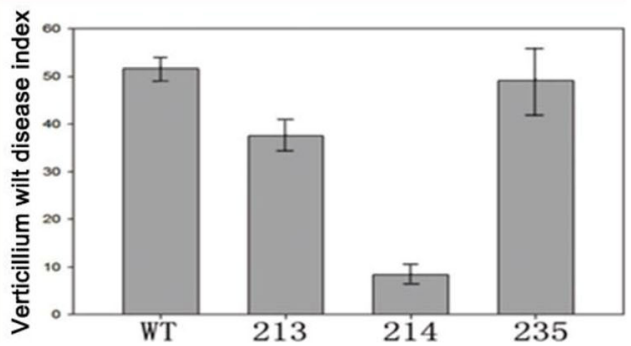

Fig. 2 The correspondence between the expression of GbAt11 and disease resistance. a Leaf phenotypes of three transgenic plants overexpressing GbAt11 and the wild type (WT, G. hirsutum JM169) after treated with Vd991 spore suspension ( $1 \times 10^{6}$ per $\left.\mathrm{mL}\right)$ for $24 \mathrm{~h}$. b Flag tagged GbAT11 protein were detected by Western blot with an anti-flag antibody. c Relative expression of GbAt11 gene in indicated plants after treated with Vd991 spore suspension $\left(1 \times 10^{6}\right.$ per $\left.\mathrm{mL}\right)$ for $24 \mathrm{~h}$. $\mathbf{d}$ Quantitative statistics of disease index in three GbAt11 overexpression lines and JM169 line treated with $V d 991$ spore suspension $\left(1 \times 10^{6}\right.$ per $\left.\mathrm{mL}\right)$ for $24 \mathrm{~h}$ 
(Wang et al. 2009) were performed in L-214 line and WT line. Clustering differentially expressed genes showed that gene transcription was significantly altered in the transgenic GbAt11-expressing line compared with the parent line. A total of 472 genes showed significant expression differences $(\mathrm{FDR}<0.01)$ (Fig. 3a). Further transcriptome analysis showed that many genes involved in "plant-pathogen interactions" (KEGG Pathway) were up-regulated in transgenic plants of GbAt11, including FLS2 and the calcium dependent protein kinase CDPK (Harmon et al. 1994; Rigo et al. 2013); RPS2, RIN4 (Rigo et al. 2013) and PBS1 (Joys 1965), which are diseaseresistance genes in ETI; and HSP90, the downstream gene in ETI. Therefore, it is reasonable to speculate that the transgenic GbAt11 line can activate ETI by affecting post-translational modifications, protein transporting and folding, relieving the inhibition of the pathogen on
PTI-based immunity and improving resistance to Verticillium wilt in cotton. To confirm the result of transcriptome, real-time PCR was conducted in three lines, and the data showed that FLS2 in L214 and L213 is extremely significant higher than WT (Fig. 3b). Nextly, 7 genes involved in ETI and PTI process were assayed via real-time PCR in L214. The results confirmed that FLS2, BAK1, MKK2, FRK1, RIN4, RPS2 genes were significantly up-regulated in transgenic line L-214, and the FLS2 gene showed the highest up-regulation (Fig. 3c).

\section{Subcellular localization of GbAT11 in Arabidopsis thaliana} We used Arabidopsis thaliana to explore the functional site of GbAT11 at the cellular level. We first produced transgenic plants of Arabidopsis thaliana expressing GbAt11-gfp, and then observed the subcellular localization of the GbAT11-GFP fusion protein in the
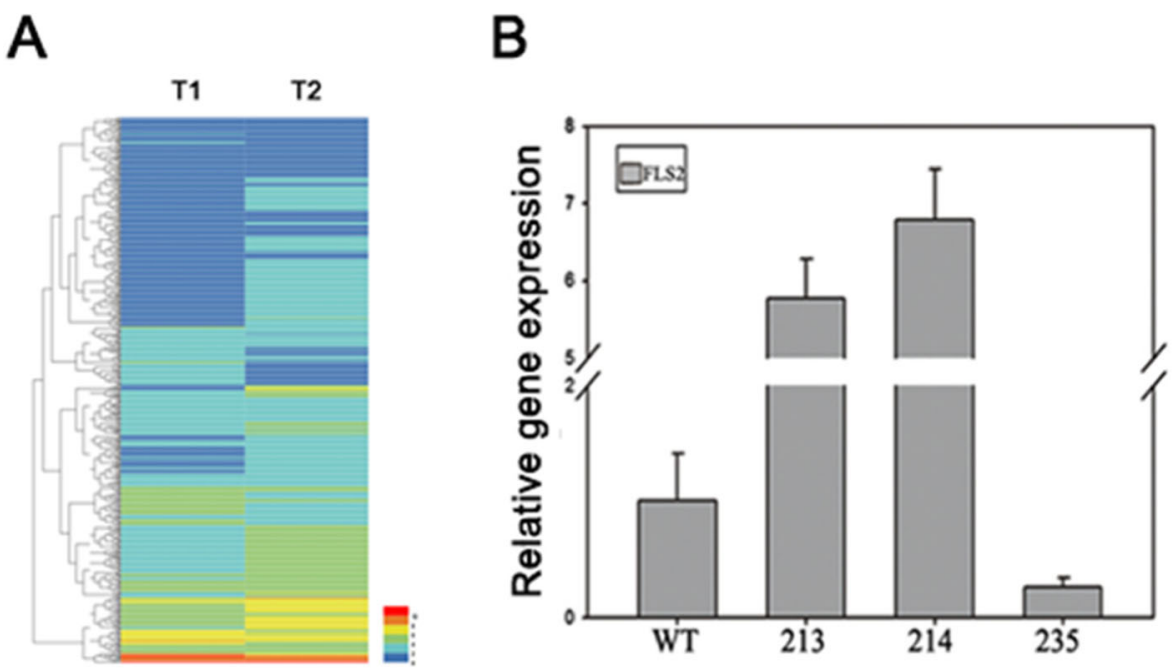

C

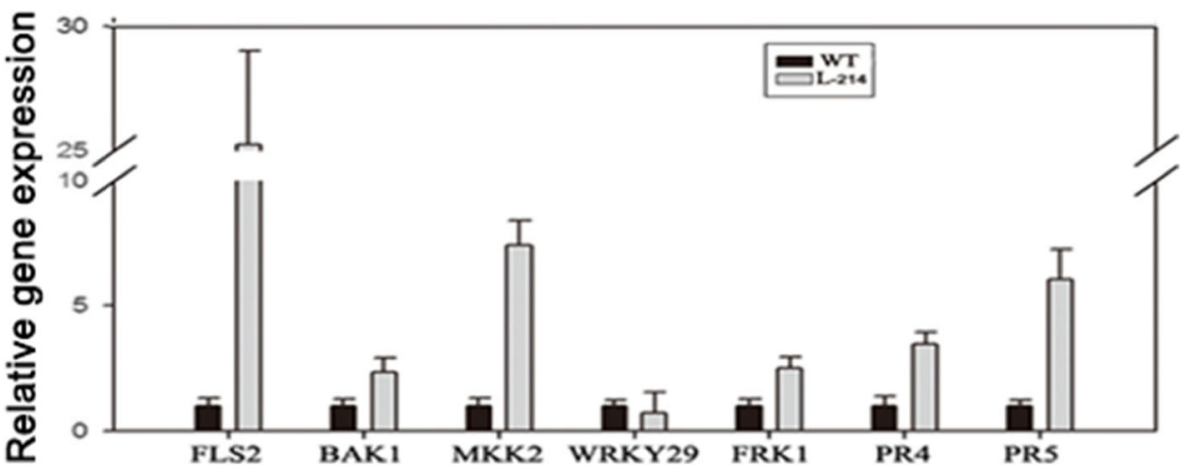

Fig. 3 GbAt11 overexpression in G. hirsutum up-regulates expression of multiple key genes in the PTI and ETI pathways a Heat map clustering of differentially expressed genes; $\mathrm{T} 1$ is the parental line JM169, and T2 is the transgenic line L-214. Colors represent the relative gene expression level in each sample; blue indicates low level of expression, and red indicates high level of expression. $\mathbf{b}$ The relative expression of FLS2 gene in indicated G. hirsutum lines. c The relative expression of indicated genes related to PTI and ETI pathway in L-214 line and the parental line JM169 


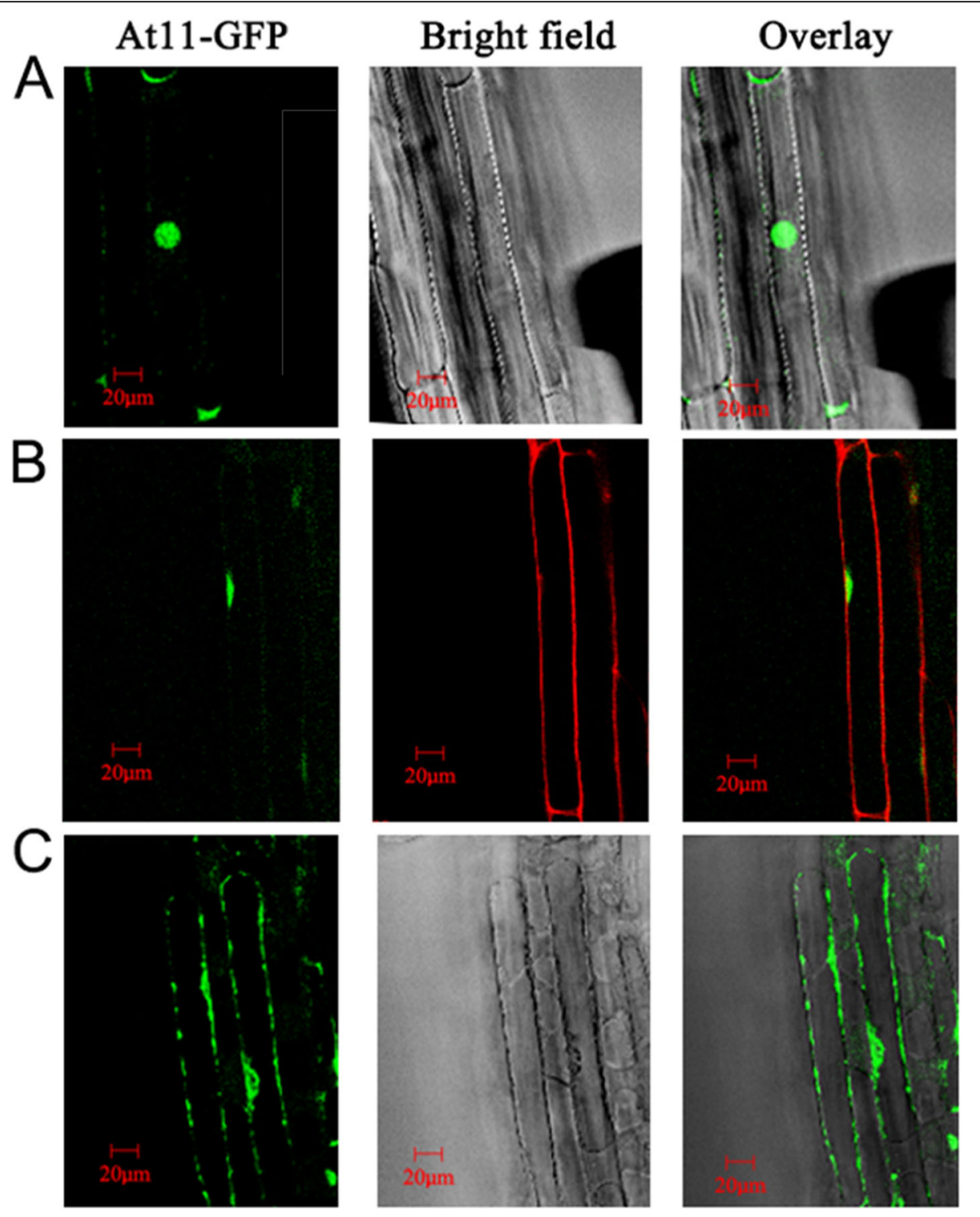

Fig. 4 Subcellular localization of GbAT11 in roots of transgenic Arabidopsis thaliana. a This image shows the localization of GFP-GbAT11 fusion protein in Arabidopsis cells, and green fluorescence appears under laser scanning confocal microscopy. $\mathbf{b}$ Laser scanning confocal microscopy showing the GbAT11 protein was localized in the nucleus after PI treatment. c Laser scanning confocal microscopy observed that GbAT11 protein was localized in the nucleus, and localized on the cell membrane after plasmolysis with $20 \%$ sucrose solution treatment of transgenic Arabidopsis thaliana roots

root tip by laser scanning confocal microscopy. The results showed that GbAT11 is mainly localized to the nucleus (Fig. 4a), and a small amount presents on the cell wall (Fig. 4b). To clarify whether GbAT11 is also located on the cell membrane in addition to the nucleus, we treated Arabidopsis root tips with a 20\% sucrose solution to separate cytoplasm from the cell wall, and then observed them under a fluorescence microscope. We found that the GbAT11-GFP protein was indeed located on the cell membrane (Fig. 4c). We also observed that the fluorescence intensity of the cell membrane was enhanced in Fig. 4c, which could be caused by shrinkage of the cell membrane, or the transfer of the GbAT11-GFP fusion protein from the nucleus to the membrane under osmotic stress.

\section{GbAt11 overexpression increase cotton yield}

A common misconception is that it is difficult to have both disease resistance and high yield in the same plant. However, our results showed that overexpression of GbAt11 not only improved disease resistance, but also increased boll-setting, which is the most important factor in cotton production. To identify the high yielding transgenic lines that overexpress GbAt11, we 


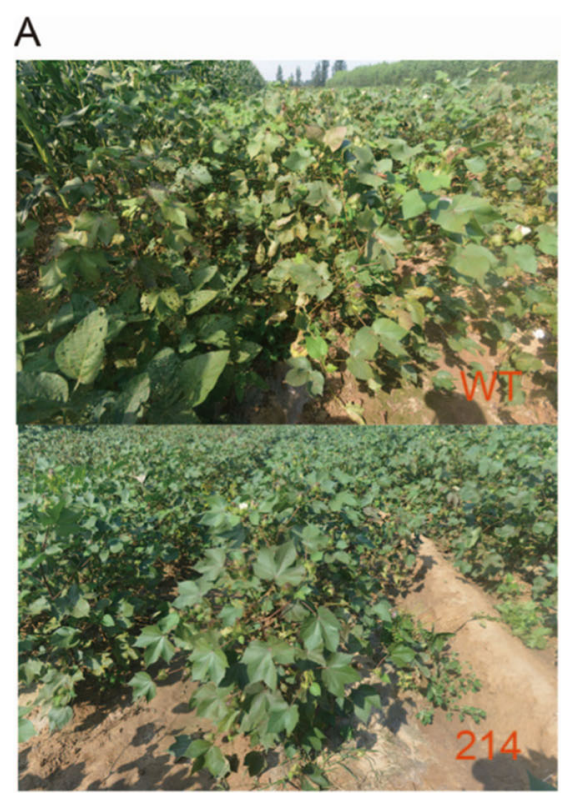

B

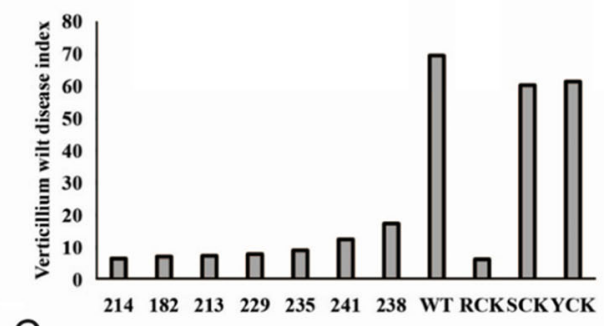

C

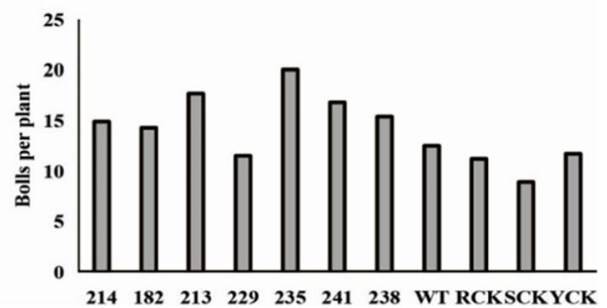

Fig. 5 Disease resistance and yield performance of GbAt11-overexpressing cotton lines and statistical results. a Boll opening phenotype of transgenic line L-214 and WT in a V. dahliae nursery at the boll opening stage (Shandong, 2013.09). b Morbidity of Verticillium wilt at the flowering and boll-forming stages. The disease index come from the results of August 20. The indexes of L-214 and other lines were significantly lower than those of WT, YCK, and SCK, but similar to RCK. c Bolls per plant at the late flowering and boll-forming stages; several lines, including L214, were better than JM169 and YCK

investigated disease severity of the transgenic lines in a $V$. dahliae nursery and also analyzed the basic yield traits, such as boll number per plant, boll opening phenotype in the field (Fig. 5a). The disease indexes of Verticillium wilt were $6.52,7.35$, and 9.09 in L-214, L213 , and L-235, respectively, and 69.44, 60.23, 6.25, and 61.36 in the wild type control (WT), the susceptible control (SCK), the disease resistant control (RCK), and the high yield control (YCK), respectively. Through analysis, it was found that the disease indexes of all transgenic lines were lower than the WT, YCK, and SCK, moreover, L-214 was extremely close to the RCK (Fig. 5b). The results showed that the bolls per plant of L-214, L213 and L-235 were 14.9, 17.6 and 20.0, respectively, and $12.5,8.9,11.2$, and 11.7 in WT, SCK, RCK, and YCK, respectively. Boll-setting in all three transgenic lines was higher than the parent lines and other controls. Other than these three lines, the bolls per plant in many other different lines were also better than YCK (Fig. 5c). In conclusion, overexpression of the GbAt11 gene in G. hirsutum not only improved its resistance to disease caused by $V$. dahliae, but also increased the number of bolls per plant in a field that was severely infested with Verticillium wilt.

\section{Discussion}

In this study, GbAt11 gene expression experiments showed that GbAt11 up-regulation started at $4 \mathrm{~h}$ after induction in G. barbadense, then decreased at $8 \mathrm{~h}$, and increased to 70 -fold at $24 \mathrm{~h}$. This result is a normal response of plants to pathogen infection: the expression of genes associated with disease resistance will increase, followed by a process of adaptation, and then expression increases again as the infection becomes severe (Denance et al. 2013). This pattern of GbAt11 expression was observed in the response of G. barbadense to infection by $V$. dahliae. As for the highly susceptible G. hirsutum, expression of genes relevant to disease resistance are not induced, but occurs systemic infection and results in leaf wilt. Thus it appears that GbAt11 plays an important role in determining Verticillium wilt resistance in G. barbadense.

Previous studies have shown that after low temperature treatment, dehydrated protein WZY2 will leave the dehydration point and disperse into the cytoplasm, indicating that low temperature will affect the distribution of wheat dehydrated protein WZY2 in cells (Lv 2014). Observing the localization of GbAT11, we can find that the cell membrane leaves the cytoplasm after the plasma wall separation occurs, and the fluorescence is localized in the cell membrane.The fluorescence brightness of the cell membrane in Fig. 4c is enhanced, which may be caused by shrinkage of the cell membrane, or when the cell is stressed, the GbAt11-GFP fusion protein localized in the nucleus is transferred to the cell membrane. 
Typically, overexpression of transcription factors, such as DRE, can improve stress tolerance or disease resistance in plants, but it may also cause dwarfing and yield reduction, etc. (Narusaka et al. 2003). We found that the cotton strain transferred to GbAt11 had a significant effect against Verticillium wilt. In addition, later production of cotton showed that the yield of transgenic cotton was higher than wild type. Although we demonstrated that the transgenic lines overexpressing GbAt11 had better resistance to Verticillium wilt, the mutant strain was failed to be constructed. Because cotton is a heterotetraploid plant, and AT11 has two copies in G. barbadense, it is difficult to knock them out together with the same vector. In addition, because of the limitation of cotton growth cycle, it is impossible to obtain double mutant in a short time. So next we will use the virus induced gene silencing system to silence the GbAt11 gene, and then further investigate the cotton resistance to Verticillium wilt. Unfortunately, we were unable to identify any proteins that directly interact with GbAT11 by coimmunoprecipitation and yeast two hybrid assays, so this remains to be further investigated in the future. Although its function needs to be further researched, the effect of increasing yield and resistance to Verticillium wilt has guiding significance to cotton production practice.

\section{Conclusion}

GbAt11 has been identified as a new gene which is specifically induced by $V$. dahliae. Its overexpression in $G$. hirsutum not only significantly improves resistance to Verticillium wilt, but also up-regulates transcription of several key genes in the immunity pathways. These results show that GbAt11 plays a role in disease resistance. Furthermore, overexpression of the GbAt11 gene in G. hirsutum can also increase the number of bolls per plant to increase cotton yield.

\section{Supplementary information}

Supplementary information accompanies this paper at https://doi.org/10 1186/s42397-020-00047-3.

Additional file 1.

Additional file 2.

Additional file 3. (XLS $215535 \mathrm{~kb}$ )

\section{Acknowledgments}

We thank Prof. GONG Zhizhong and Prof. LI Jigang of the Department of Plant Science, College of Biological Sciences of China Agricultural University for their assistance. We gratefully acknowledge the State Key Laboratory of Plant Physiology and Biochemistry for allowing this work to take places in their laboratory.

\section{Authors' contributions}

Qi JS conceived and initiated the research. Qi JS, Qiu TT, Wang YJ and Jiang J performed the experiments. Qi JS, Qiu TT, Wang YJ and Zhao J analyzed the data. Qi JS, Qiu TT, Wang YJ and Jiang J wrote the article. The authors read and approved the final manuscript.

\section{Funding}

This research was financially supported by the National Key Research and Development Program of China (2016YFD0101904).

\section{Availability of data and materials}

The source data underlying Figs.1, 2, 3, 4 and 5 are provided as a Source Data file. All other data that support the findings of this study are available from the corresponding author upon request.

\section{Ethics approval}

This study was approved by the local ethics committee.

Consent for publication

We accept publication.

\section{Competing interests}

The authors declare that they have no competing interests.

Received: 16 October 2019 Accepted: 26 February 2020

Published online: 14 April 2020

References

Adachi $\mathrm{H}$, Nakano T, Miyagawa N, et al. WRKY transcription factors phosphorylated by MAPK regulate a plant immune NADPH oxidase in Nicotiana benthamiana. Plant Cell. 2015;27(9):2645-63. https://doi.org/10. 1105/tpc.15.00213

Albrecht C, Boutrot F, Segonzac C, et al. Brassinosteroids inhibit pathogenassociated molecular pattern-triggered immune signaling independent of the receptor kinase BAK1. PNAS. 2012;109(1):303-8. https://doi.org/10.1073/ pnas.1109921108.

Albrecht C, Russinova E, Kemmerling B, et al. Arabidopsis SOMATIC EMBRYOGENESIS RECEPTOR KINASE proteins serve brassinosteroiddependent and -independent signaling pathways. Plant Physiol. 2008;148(1): 611-9. https://doi.org/10.1104/pp.108.123216.

Asai T, Tena G, Plotnikova J, et al. MAP kinase signalling cascade in Arabidopsis innate immunity. Nature. 2002;415(6875):977-83. https://doi.org/10.1038/ 415977a.

Burpee LL, Bloom JR. The influence of Pratylenchus penetrans on the incidence and severity of Verticillium wilt of potato. J Nematol. 1978;10(1):95-9.

Denance N, Sanchez-Vallet A, Goffner D, Molina A. Disease resistance or growth: the role of plant hormones in balancing immune responses and fitness costs. Front Plant Sci. 2013;4:155. https://doi.org/10.3389/fpls.2013.00155.

Diatchenko L, Lau Y, Campbell AP, et al. Suppression subtractive hybridization: a method for generating differentially regulated or tissue-specific cDNA probes and libraries. PNAS. 1996;93(12):6025-30. https://doi.org/10.1073/pnas.93.12. 6025.

Fradin EF, Abd-El-Haliem A, Masini L, et al. Interfamily transfer of tomato Ve1 mediates Verticillium resistance in Arabidopsis. Plant Physiol. 2011;156(4): 2255-65. https://doi.org/10.1104/pp.111.180067.

Fradin EF, Zhang Z, Ayala JCJ, et al. Genetic dissection of Verticillium wilt resistance mediated by tomato Ve1. Plant Physiol. 2009;150(1):320-32. https://doi.org/10.1104/pp.109.136762.

Gao X, Wheeler T, Li Z, et al. Silencing GhNDR1 and GhMKK2 compromises cotton resistance to Verticillium wilt. Plant J. 2011;66(2):293-305. https://doi.org/10. 1111/j.1365-313X.2011.04491.X.

Gomez-Gomez L, Boller T. FLS2: an LRR receptor-like kinase involved in the perception of the bacterial elicitor flagellin in Arabidopsis. Mol Cell. 2000;5(6): 1003-11. https://doi.org/10.1016/s1097-2765(00)80265-8.

Harmon AC, Yoo BC, Mccaffery C. Pseudosubstrate inhibition of CDPK, a protein kinase with a calmodulin-like domain. Biochemistry. 1994;33(23):7278-87. https://doi.org/10.1021/bi00189a032.

Joys TM. Correlation between susceptibility to bacteriophage PBS1 and motility in Bacillus subtilis. J Bacteriol. 1965;90(6):1575-7.

Kawchuk LM, Hachey J, Lynch DR, et al. Tomato Ve disease resistance genes encode cell surface-like receptors. PNAS. 2001;98(11):6511-5. https://doi.org/ 10.1073/pnas.091114198. 
Lin W, Lu D, Gao X, et al. Inverse modulation of plant immune and brassinosteroid signaling pathways by the receptor-like cytoplasmic kinase BIK1. PNAS. 2013;110(29):12114-9. https://doi.org/10.1073/pnas.1302154110.

Lv D. The effect of cold stress on subcellular localization of wheat Dehydrin WZY2. Yangling: North West Agriculture and Forestry University; 2014. p. 156.

Narusaka Y, Nakashima K, Shinwari ZK, et al. Interaction between two cis-acting elements ABRE and DRE in ABA-dependent expression of Arabidopsis rd29A gene in response to dehydration and high-salinity stresses. Plant J. 2003; 34(2):137-48. https://doi.org/10.1046/j.1365-313x.2003.01708.x.

Nurnberger T, Brunner F, Kemmerling B, Piater L. Innate immunity in plants and animals: striking similarities and obvious differences. Immunol Rev. 2004;198: 249-66. https://doi.org/10.1111/j.0105-2896.2004.0119.x.

Ozinsky A, Underhill DM, Fontenot JD, et al. The repertoire for pattern recognition of pathogens by the innate immune system is defined by cooperation between toll-like receptors. PNAS. 2000;97(25):13766-71. https:// doi.org/10.1073/pnas.250476497.

Qi X, Su X, Guo H, et al. VdThit, a thiamine transport protein, is required for pathogenicity of the vascular pathogen Verticillium dahliae. Mol Plantmicrobe In. 2016;29(7):545-59. https://doi.org/10.1094/MPMI-03-16-0057-R.

Rigo G, Ayaydin F, Tietz O, et al. Inactivation of plasma membrane-localized CDPK-related kinase5 decelerates PIN2 exocytosis and root gravitropic response in Arabidopsis. Plant Cell. 2013;25(5):1592-608. https://doi.org/10. 1105/tpc.113.110452.

Salin C, Sunchai P, Apiradee T. Dengue typing assay based on real-time PCR using SYBR green I. J Virol Methods. 2005;129(1):8-15. https://doi.org/10. 1016/j.jviromet.2005.05.006.

Simko I, Costanzo S, Haynes KG, et al. Linkage disequilibrium mapping of a Verticillium dahliae resistance quantitative trait locus in tetraploid potato (Solanum tuberosum) through a candidate gene approach. Theor Appl Genet. 2004;108(2):217-24. https://doi.org/10.1007/s00122-003-1431-9.

Wan J, Zhang XC, Stacey G. Chitin signaling and plant disease resistance. Plant Signal Behav. 2008;3(10):831-3. https://doi.org/10.4161/psb.3.10.5916.

Wang Z, Gerstein M, Snyder M. RNA-Seq: a revolutionary tool for transcriptomics. Nat Rev Genet. 2009;10(1):57-63. https://doi.org/10.1038/nrg2484.

Zhang T, Chen T. Cotton pistil drip transformation method. Methods Mol Biol. 2012;847:237-43. https://doi.org/10.1007/978-1-61779-558-9_20.

Zhang Y, Wang XF, Li YY, et al. Ectopic expression of a novel Ser/Thr protein kinase from cotton (Gossypium barbadense), enhances resistance to Verticillium dahliae infection and oxidative stress in Arabidopsis. Plant Cell Rep. 2013;32(11):1703-13. https://doi.org/10.1007/s00299-013-1481-7.

Zhang Y, Wang XF, Yang $S$, et al. Cloning and characterization of a Verticillium wilt resistance gene from Gossypium barbadense and functional analysis in Arabidopsis thaliana. Plant Cell Rep. 2011;30(11):2085-96. https://doi.org/10. 1007/s00299-011-1115-X.

Ready to submit your research? Choose BMC and benefit from:

- fast, convenient online submission

- thorough peer review by experienced researchers in your field

- rapid publication on acceptance

- support for research data, including large and complex data types

- gold Open Access which fosters wider collaboration and increased citations

- maximum visibility for your research: over $100 \mathrm{M}$ website views per year

At BMC, research is always in progress.

Learn more biomedcentral.com/submissions 